\title{
Are We Ready to Go Live with Our Team Projects?
}

\author{
Janice Whatley \\ Manchester Metropolitan University, Manchester, UK
}

\author{
j.whatley@mmu.ac.uk
}

\begin{abstract}
Project work forms a large part in work undertaken by graduates when they enter the workforce, so projects are used in higher education to prepare students for their working lives and to enable students to apply creativity in their studies as they present a solution to a problem, using technical skills they have learned in different units of study. Projects, both at work and in higher education, may be completed in teams, thus providing experience and the opportunity to develop team working skills. The team projects presented in this paper have been provided by external organisations, so that students work in a team on a real life problem, but with the support of their tutors, in the university setting. In this way the projects more closely resemble the sorts of problems they might encounter in the workplace, giving an experience that cannot be gained by working on tutor devised problems, because the teams have to communicate with an external client to analyse and solve an authentic problem.

Over the three years that the Live Projects have been running, feedback indicates that the students gain employability skills from the projects, and the organisations involved develop links with the university and benefit from output from the projects. A number of suggestions for improving the administration of the Live Projects were suggested, such as providing clients with information on timescales and providing students with more guidance on managing the projects.
\end{abstract}

Keywords: Team project, employability, transferable skills, external client.

\section{Introduction}

Learning in higher educational establishments has traditionally been concerned with learning about and formulating theories. Over time, and partly driven by demands of industry, some universities have incorporated project or problem based learning into the teaching and learning methods used, to provide students with opportunities to develop some of the skills demanded by industry. Team project working provides a means to help students to acquire skills required by industry, and these are incorporated into the curriculum at universities in a range of different ways. Benefits of using team projects include experience of team work, providing an opportunity to practice some of the theory being taught and collaborative problem solv-

Material published as part of this publication, either on-line or in print, is copyrighted by the Informing Science Institute. Permission to make digital or paper copy of part or all of these works for personal or classroom use is granted without fee provided that the copies are not made or distributed for profit or commercial advantage AND that copies 1) bear this notice in full and 2) give the full citation on the first page. It is permissible to abstract these works so long as credit is given. To copy in all other cases or to republish or to post on a server or to redistribute to lists requires specific permission and payment of a fee. Contact Publisher@InformingScience.org to request redistribution permission. ing.

This paper presents an example of using team projects for undergraduate computing students, whilst at the same time working with external organisations who are keen to develop closer links with the university. The venture is called the "Live Projects Scheme", which was started three years ago and has proved to 
be popular with students, tutors and the organisations involved. The paper is written from the perspective of the tutor charged with sourcing the projects for the student teams and presents feedback from students and clients.

\section{Pedagogical Assumptions of Teaching with Team Projects}

The term "graduate employability" encompasses a number of elements, such as knowledge and skills and personal self-esteem. Generic skills or transferable skills have varying listings, but most commonly used lists include working in a team, creativity, planning and communication (Dacre Pool \& Sewell, 2007). Higher education institutions are taking up the challenge of preparing students for work, by teaching skills associated with employability, such as team work (Dacre Pool \& Sewell, 2007; Prichard, Stratford, \& Bizo, 2006; Yorke \& Knight, 2003)). According to Hordyk (2007) employers can benefit from universities teaching employability skills, through an improved competitive edge, performance, and profitability, but it is acknowledged that team work in the student context is different from that identified in the workplace.

Government bodies, notably in the UK, have recommended including key skills in the teaching curriculum since the 1950s, in the guise of "core skills", "key skills" or "general skills", aimed at preparing people for the world of work (Edwards, 2005). These included literacy, numeracy and information technology, and are enshrined in compulsory education (Hyland \& Johnson, 1998), but other skills such as "working with others", "presenting", "problem solving" and "managing own learning", were added after the Dearing review of post-compulsory education in 1996. However, Hyland and Johnson (1998) argue that these latter skills are context specific and so cannot be taught as generalised or transferable skills, but that opportunities or experiences are the best way to help learners to acquire these skills.

Management competencies, such as empowerment, development and feedback, interest and ethics, are cited as important in business, from the perspective of managing other people (Cripe \& Mansfield, 2002). On the other hand self-confidence, credibility, and flexibility are included from the perspective of all staff. According to the Quality Assurance Agency in the UK, there are a number of additional skills that undergraduate students should have an opportunity to develop through experience, as outlined in the Computing Subject Benchmark document published in 2007 (Figure 1).

Effective information-retrieval skills (including the use of browsers, search engines and catalogues).

Numeracy and literacy in both understanding and presenting cases involving a quantitative and qualitative dimension.

Effective use of general information technology (IT) facilities.

The ability to work as a member of a development team, recognising the different roles within a team and different ways of organising teams.

Managing one's own learning and development including time management and organisational skills.

Appreciating the need for continuing professional development in recognition of the need for lifelong learning.

Figure 1 - Additional transferable skills.

(Quality Assurance Agency for Higher Education, 2007) 
In designing the computing curriculum the same document suggests that the following should be provided for:

- in practical coursework there is an opportunity for students to gain experience of working both in groups and as an individual;

- in relevant parts of the course students are encouraged to reflect, evaluate, select, justify, communicate and be innovative in their problem-solving;

- the development of a range of personal and transferable skills generic to all graduates;

- a major activity allowing students to demonstrate ability in applying practical and analytical skills (as they are present in the course as a whole). This will often take the form of a project carried out in the final year, but individual higher education institutions (HEIs) are free to use alternative arrangements where that would best fit their particular course structure or content.

In organisations there is a growing use of team work, and universities are required to produce graduates with knowledge and experience in team work. A team project gives an opportunity to learn from mistakes and to develop collective and individual skills (Fellers, 1996). According to Atherton (2005), the range of activities, linking them together and synthesising the problems, provides opportunities for developing cognitive, affective, and psycho-motor skills. Team projects incorporate elements of collaborative and co-operative working, promoting team work skills acquisition (Prichard et al., 2006) and enabling learning in a social situation.

Project based learning has the capability of bringing together learning through experimentation and learning by doing. In subjects such as programming, classroom instruction is usually supported by practical work (Poindexter, 2003). Project based learning is a form of constructivist and collaborative learning, allowing several students to work together on a problem and learn from each other as they co-construct knowledge (Beckmann, 1998). Carrying out projects in a team, involves both co-operative and collaborative learning. Learning may be considered co-operative, because individuals rely on each other to perform their allocated parts of the project (Johnson, Johnson, \& Smith, 1991), but also collaborative as they develop synthesis and application skills by working together. Co-operative learning can be regarded as process driven, but it does require attention to social processes in order to achieve the goal of the team (McConnell, 2000).

Mergendollar (2006) suggests that team projects are one form of problem based learning (PBL) in which learners are self-directed, assisted by guidance or coaching from tutors, in their pursuit of a solution to a problem. Team project based learning provides greater learning opportunities than problem based learning on its own, so team projects, particularly in the computing discipline, are a good way to promote constructivist learning and team work in an experiential and practical learning environment (Griffiths \& Partington, 1992).

Blumenfeld et al. (1991) describe project based learning as "a comprehensive approach to classroom teaching and learning that is designed to engage students in investigation of authentic problems". The case described in this paper is based on team project based learning, requiring hands-on, active learning to investigate and resolve a messy real-world problem.

The desired outcomes from student team projects are learning about team work processes, project management, problem solving, and communication, together with skills associated with the products of the tasks; so the team project becomes a vehicle for experiential learning. However, it is very difficult to assess the degree of developing these skills, unless students are given an opportunity to reflect on their performance in team work. Personal development planning (PDP) literature talks about team work skills, but does not specify what sorts of skills, or how they can be acquired (Edwards, 2005). Joy (2005) suggests that only skills such as programming in a particular language or web site design can be assessed as learning skills against given criteria, the softer skills cannot be easily measured. 
Livingstone and Lynch (2000) suggest that team projects need to be structured if they are to provide maximum benefit to students, which is the opposite of arguments in favour of pure problem based learning activities. One proposed structure for project based learning is the division of activities into process oriented and product oriented components (Whatley, 2012).

There is some debate concerning the extent to which team projects in an educational setting can prepare students for team work in the workplace (Dunne \& Rawlins, 2000). In the field of health teaching, a study comparing the effectiveness of problem based learning (PBL) and team projects did cast doubt on whether PBL does indeed help to develop transferable skills suitable for project working in the workplace (Mennin, 2007). Further, it is noted by Hordyk (2007) that there is a need for further understanding of the differences between project team work in the workplace and in the educational setting. Hyland and Johnson (1998) say that any skills learned can apply only to that context, suggesting that there is no such thing as a transferable skill. Other studies carried out in higher education do suggest that the results may be transferred to the workplace, e.g., problem solving skills (Banks \& Millward, 2007; Lou, 2004; Mennin, 2007; Murthy \& Kerr, 2003).

Arguments in favour of using team projects in teaching do outweigh those against, but incorporating team projects into the curriculum is not without its difficulties. Many students are offered an optional placement or intern year as part of their programme of study, and this has been found to be one of the best learning experiences that undergraduate students can have for developing employability skills and encouraging reflection on learning. Not all students are able to take up such an opportunity, so is it possible to provide an experience at the higher educational establishment that can provide some of the benefits of working for an employer?

The case described in this paper is a unit of study that includes a Live Project as part of the second year of undergraduate study. The rationale for this was to provide an opportunity to develop employability skills, whilst working in a team and solving a real world problem.

\section{Live Projects in Action}

Three years ago (in 2013) the Live Projects were introduced in the Computing and Mathematics School for the computing programmes, including computing, computer science, and software engineering. Second year undergraduate students on these programmes take a year-long unit called Professional Development, which incorporated a tutor provided team project, to give experience of team work, communication, and project management. The unit starts with some ethical and legal issues, such as data protection, intellectual property rights, computer misuse, freedom of information legislation and codes of conduct of professional bodies related to computing. After six weeks of lectures and tutorial work on ethical and legal issues, the students sit an online test, as a part of accreditation for the British Computer Society. The team projects are then introduced to the students, and teams of about 8 students work on these projects for the remaining 16 weeks of the academic year. The university was looking for ways to engage local businesses and organisations, in addition to providing internships for students, and providing small projects for students to complete as part of their studies was suggested. These would provide real life problems to work on, unique to each team, and allow external businesses to engage closely with the work of the university.

What started as an experiment three years ago, when the university was able to provide 8 teams with a Live Project, grew to 15 projects in the second year, and to 25 Live Projects in the third year. These are projects from a variety of external organisations, from small start-up businesses run by an individual, to small charitable ventures in need of some low cost help, and some of the larger companies in the Manchester area. The problems presented to the students range from designing and building a web site, or setting up a database system to support customer online searches, to producing an app that visitors can use to find more information in a museum. Each 
year there are about 250 students taking the unit, supported by ten tutors, and the students are divided into teams of about 8 members for the projects. Students are given a choice of whether to undertake a Live Project or an academic provided project.

The process of sourcing projects continues throughout the year, but is stepped up between August and September in order to have projects ready for the students by the end of October. Approaches are made to local organisations who have already expressed an interest in working more closely with the university. These are often leads from the placements tutor or visitors to other events at the university. Local placement fairs are another source of useful contacts, and a promotional flyer is used to raise awareness of the Live Projects Scheme. After three years of running the scheme, other tutors are now bringing their organisational contacts into the scheme, and contact through the embryo business arm of the university provides start-up businesses interested in assistance to develop their ventures.

Clients are asked to provide a project that, whilst not mission critical, does have importance in their business context. The project should be small enough to be completed within about 12 weeks and yet complex enough for a team of around 8 students to get their teeth into. All projects are different so it can be difficult to ensure that all of them provide equivalent experiences, but projects that lack depth of technical work will often provide opportunity for team members to research and evaluate other aspects of the problem area.

When about 12 projects are confirmed, the list is sent around the ten tutors involved in the unit, who can make initial selections of projects more suited to their students, and as new projects are agreed this list is extended. Each tutor will have between 15 and 32 students in their tutorial slot, so between 2 and 4 groups of 8 students in each. An optional "academic" project is also provided for each cohort, giving a choice for those who do not wish to take on the added responsibility of working for an external client.

Using the Moodle learning management system (LMS), group discussion areas are created for all of the tutorial cohorts, and when tutors have selected their projects, these are linked to separate group areas, providing the students with a short paragraph about the project. Students within their tutorial slot can assign themselves to a chosen group and project. Figure 2 shows group forums set up for one of the tutorial cohorts.

One additional feature of the way the Live Projects works is that team structures are defined from the beginning, so students can elect to take on the role of Team Leader, Deputy Team Leader, Finance Director, Marketing Leader or Sub-team Leader. Students indicate their preference for a role as they assign to a group, and some negotiation, between team members and possibly the tutor, may be needed if more than one person indicates preference for a particular role. Students are also encouraged to evaluate their Belbin types and use these to help choose roles within a team. Around the beginning of November the students will have assigned themselves to a team, and the contact details for their chosen project client are posted to the group forum.

Teams are supported in their project work in two main ways: each week there is a lecture slot where either one aspect of team or project working is covered, e.g., project management or team cohesion, or a question and answer session where one of the teams comes to the whole class with an issue that has arisen in their group, to engage the audience in discussion of possible solutions. In addition, a two hour tutorial slot in a computer lab is timetabled, for teams to meet together each week, and meet with their tutor to discuss progress and any issues. 


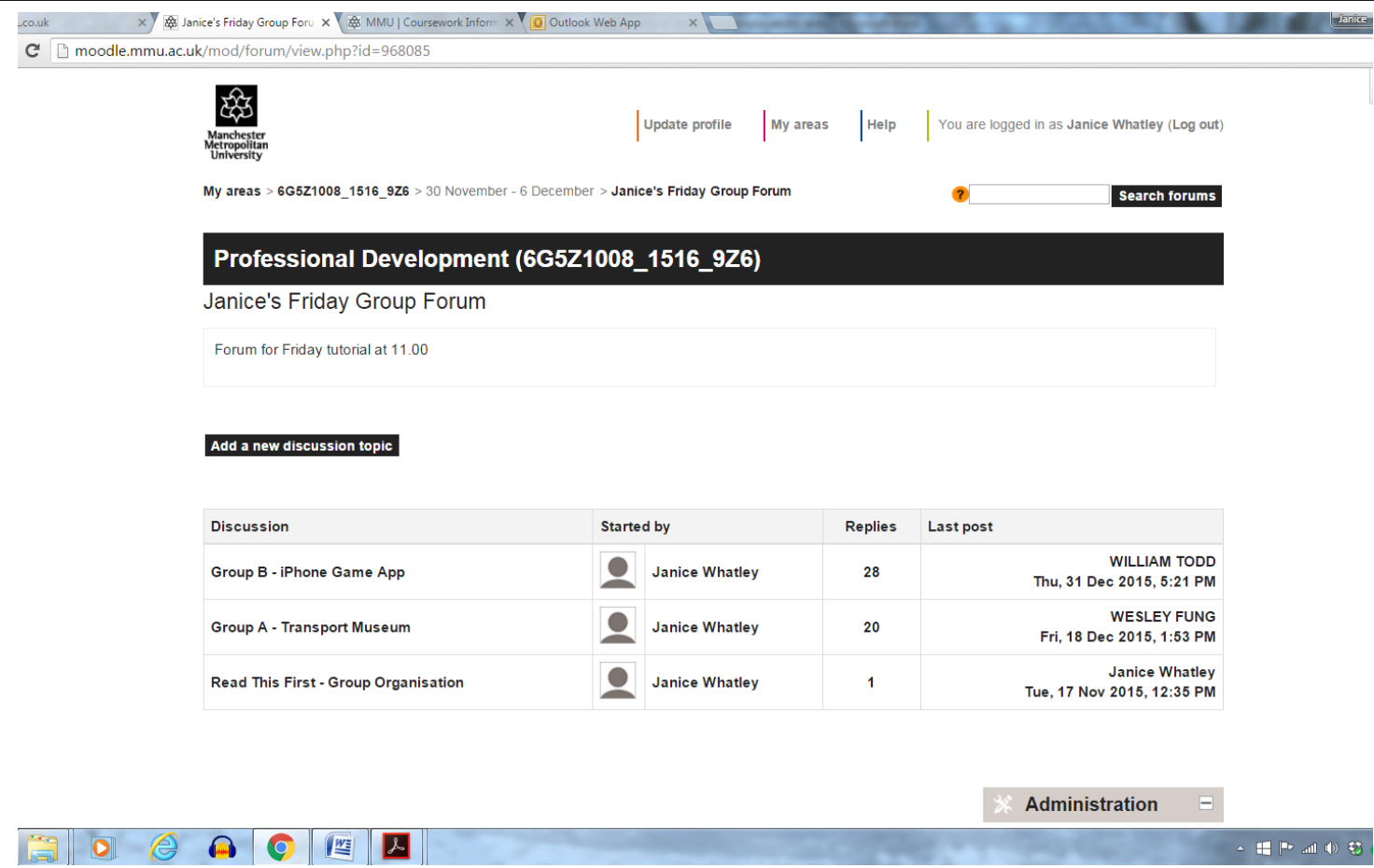

Figure 2 - Example of forums set up for two typical Live Projects in Moodle LMS.

An example schedule for deliverables is as follows:

\begin{tabular}{|l|l|}
\hline Milestone & Submission date 2016 \\
\hline Project Plan and Business Plan submission & $22^{\text {nd }}$ January \\
\hline Final Report submission & $18^{\text {th }}$ March \\
\hline Live Projects Showcase & Friday $15^{\text {th }}$ April \\
\hline
\end{tabular}

It is suggested that the team tries to contact their client to arrange a meeting as soon as their team is finalised, so that by the end of the autumn term the team will have met with the client, and they can start preparing a project plan, ready to start work in earnest at the beginning of January. The first milestone of project plan and business plan is submitted for formative feedback from the tutor, so does not contribute to the final project grade. It does however ensure that the team have made contact with their client and established the main objectives of the project. Each team member must write a section of the final report submission, detailing the contribution they have made to the project outputs, and this is used for grading purposes.

When the projects have drawn to a close, there is a Projects Showcase, as an alternative means of presenting the outcomes of their projects. All teams present at the Showcase, whether they have completed a Live Project or an academic provided project, a total of about 35 teams. Live Project clients are invited, together with prospective clients, other university partners, members of staff, and first year computing students. 


\section{Findings from Three Years of Live Projects}

At the end of the Live Projects students were asked the following questions:

What did you think was good about doing the Live Project?

What did you not like about doing the Live Project?

What skills do you think you gained by doing the Live Project?

One aspect that students did feel was good about the Live Projects was the experience of working with a real business:

It allowed me to learn a good amount of detail about each specific role within a business. Talking with someone from a business was great and gave us a lot of information about the current industry and where it looked to be heading.

Working together with an actual client. The client gave us criteria, feedback, suggestions and information on what they required for the project. It gave us some experience in dealing with real clients and also with working within a large group.

It gave me a good experience of working in the real world, and making decisions myself, instead of them being picked for me.

Amongst the feedback on things the students did not like, the difficulty of sourcing projects of similar scope was noted, together with deficiencies in tutor support and perceived unfairness of grades awarded to individuals:

The thing that seems unfair to me is the fact that every group has a different client and this can give an unfair advantage to some groups over others. But this is how the real world works so I guess its further experience.

How unorganised it was. Also there wasn't enough information in the lectures on each role, too much on finance.

Marking scheme, each member should be marked individually for their part and another mark for an overall group mark, some members have contributed greatly towards the project whilst some haven't even bothered. Yet they will still receive roughly the same mark even though the contribution toward is different.

When the students were asked what skills they thought they had gained, leadership, communication and organisation skills were mentioned, and two responses were as follows:

I think it built up my confidence and give me more insight into working as a team in a work environment.

I have learnt what I am best at in a team, and how to handle a group of people.

Clients were asked to rate the performance of their team, considering their understanding of the business context, problem solving ability, performance in meetings, effectiveness of communication, project reporting and team organisation. Comments included the following:

Considering they had no previous knowledge of our organisation, the group have gained considerable understanding about our processes.

The group were well organised considering the size of group and the amount of ideas from each member pitched in initial meetings. The team became more organised as the project concluded. 
The team were effective and professional in meetings, although it was felt that the team could have been better prepared for some meetings

Communications were professional, timely and effective.

Yes, the group were extremely knowledgeable and understood the requirements of the brief. The team also made suggestions for functionality and ideas that might work best aesthetically, based on existing websites which was incredibly helpful.

The group produced a report filled with design decisions which will allow us to see different ways to solve the problem.

The amount of work they have produced is above and beyond what we were expecting.

Some clients did note that their team fell short on a number of the criteria:

It seemed like a great idea, excellent opportunity for us to engage with students and to have a fresh approach to a project. I think it needs to be managed much more closely as the group did not seem responsive or engaged and I found it very hard to get in touch with them.

I'm not sure the team knows that IT is about focussing on the customer and that is the most important part of any plan - it may be good to focus more on the customer in future Live Projects so that it reflects what projects are like in companies

Showcase Feedback indicated that the students and staff appreciate the event as a vibrant and enthusiastic time, which does give students an opportunity to present outcomes from the project in a different format, another valuable skill in the workplace.

\section{Discussion of Issues that Arise}

The range of different clients does mean that projects vary in their complexity and user requirements, and may progress in different ways, but Kozlowski and Ilgen (2006) point out that project teams do need to be flexible and adapt to the unexpected. Salas, Cooke, and Rosen (2008) includes multiple and concurrent tasks, uncertainty, changing plans, and high workload as factors that affect team performance, and these are all often seen in the Live Projects, providing some experience of projects in the real world for the student teams. There are occasions when the client tries to add extra tasks to the project brief, and the tutor needs to be careful to prevent the workload becoming too onerous. Some projects may seem trivial, but in these cases students may take the opportunity to learn about other aspects of the project, for example learning a new programming skill.

Assessing individuals within their teams in a fair manner can be difficult, and the tutors need to work to the same guidelines in order to provide equitable grading across different teams. Each project is different, so assessing the product is not appropriate, and the unit learning outcomes are around their skills development rather than technical product. Assessment is based around a grade for the overall project process and a peer assessment grade. Students also have to make an individual podcast where they explain the contribution they have made to the project outputs, and this is considered alongside the chapter of the project report that each individual writes regarding their part of the project.

The final project report produced is not structured as a business report would be, because each team member has to contribute a chapter about the part of the project they took responsibility for. They are encouraged to reflect on their performance and to be critical of errors and limitations, which would not usually appear in a project report. However, the report is also part of the deliverables for the client, so should contain relevant information on research and work undertaken to produce the outputs. 
At the beginning of the academic year, the students cover material for ethical and legal aspects of business and do not start their projects until this has been completed, but the students did comment that they would like to start their projects sooner:

I think that if the project was started or put into place during the first part of the year when the legal aspects are being discussed, and people then have their groups and some sort of insight to what is going to happen so they can maybe plan something in their own time.

A need for more information was voiced from students:

Ifelt that there was lack of guidance from the start, unless we asked for it. Which can be good. "How do we start this project" was the first question that cane to my head. I think you should explain to the groups the starting stages of the project, e.g. talk to your client.

Also clients felt they could do with more information:

If there was more bit more information provided by the university to the client, I feel I would have been able to set workloads appropriately to better last the duration of the module.

The group size for future projects of this nature could be considered, and written action plans with timescales for the project distributed to everyone involved.

The size of the teams does make communication difficult between team members. Communication within the student teams and with clients is important, and knowing who knows what is part of transactive memory, that needs to also be managed by the team (Kozlowski \& Ilgen, 2006). Teams are encouraged to use the forums set up on the learning management system, which provides a minimum level of communication support, and can be supplemented by other forms of communication media, such as Facebook, DropBox or Google Docs.

\section{Conclusions and Future Work}

The idea of using real life projects provided by external organisations gives an element of authentic problem solving to this unit of study, and the students come to appreciate how the particular problem fits into the overall business. Clients benefit from the input of students, as they may bring new insights to their problem area, and clients receive help at minimal cost, especially useful for start-up ventures or charitable organisations. The university is developing new and deeper relationships with client organisations, and although there is some effort required in developing links with local organisations and forming an appropriate project, there are benefits to the university, the students, and future employers in this venture.

Students are being assessed on the "process" of the project rather than the "product", so the fact that all projects are different, with varying levels of complexity, does not affect the learning outcomes. Students reported that they have indeed developed new skills, which will be useful in the workplace, and many have successfully undertaken placement years after completing the Professional Development unit.

Several limitations in the way the Live Projects were organised were identified, and these will be considered when preparing for the unit in coming years. For example clients suggested that they would like more information on timescales, so that work could be better designed to fit in with university deadlines, and clearer guidelines on how to organise meetings with clients could be given to the students. 


\section{References}

Atherton, J. S. (2005). Learning and teaching: Bloom's taxonomy. Retrieved 10 October 2007 from http://www.learningandteaching.info/learning/bloomtax.htm

Banks, A. P., \& Millward, L. J. (2007). Differentiating knowledge in teams: The effect of shared declarative and procedural knowledge on team performance. Group Dynamics, 11(2), 95-106.

Beckmann, J. (1998). Project based learning. Web. Retrieved from http://www.edutopia.org/blog/assessingproject-based-learning-how-to-suzie-boss

Blumenfeld, P., Soloway, E., Marx, R., Krajcik, J., Guzdial, M., \& Palincsar, A. (1991). Motivating project-based learning: Sustaining the doing, supporting the learning. Educational Psychologist, 26(3, 4), 369-398.

Cripe, E. J., \& Mansfield, R. S. (2002). The value-added employee: Workitect Inc.

Dacre Pool, L., \& Sewell, P. (2007). The key to employability: Developing a practical model of graduate employability. Education and Training, 49(4), 277-289.

Dunne, E., \& Rawlins, M. (2000). Bridging the gap between industry and higher education: Training academics to promote student teamwork. Innovations in Education and Teaching International, 37(4), 361-371.

Edwards, G. (2005). Connecting PDP to Employer Needs and the World of Work. Retrieved September 2007, from http://www.heacademy.ac.uk/resources/detail/id71_connecting_pdp_edwards

Fellers, J. (1996). Teaching teamwork: Exploring the use of cooperative learning teams in information systems education. The DATABASE for Advances in Information Systems, 27(2), 44-60.

Griffiths, S., \& Partington, P. (1992). Enabling active learning in small groups. CVCP, Sheffield.

Hordyk, V. (2007). A convergence of perspectives: Enhancing students' employability. Paper presented at the Education in a Changing Environment, Salford, UK.

Hyland, T., \& Johnson, S. (1998). Of cabbages and key skills: Exploding the mythology of core transferable skills in post-school education. Journal of Further and Higher Education, 22(2), 163-172.

Johnson, D. W., Johnson, R. T., \& Smith, K. A. (1991). Cooperative learning:increasing college faculty instructional productivity. Washington, D.C.: School of Education and Human Development, George Washington University.

Joy, M. (2005). Group projects and the computer science curriculum. Innovations in Education and Teaching International, 42(1), 15-25.

Kozlowski, S. W. J., \& Ilgen, D. R. (2006). Enhancing the effectiveness of work groups and teams. Psychological Science in the Public Interest, 7(3), 77-124.

Livingstone, D., \& Lynch, K. (2000). Group project work and student-centred active learning: Two different experiences. Studies in Higher Education, 25(3), 325-345.

Lou, Y. (2004). Learning to solve complex problems through between-group collaboration in project-based online courses. Distance Education, 25(1), 49-66.

McConnell, D. (2000). Implementing computer supported cooperative learning (2nd ed.). London: Kogan Page.

Mennin, S. (2007). Small-group problem based learning as a complex adaptive system. Teaching and Teacher Education, 23, 303-313.

Mergendollar, J. (2006). The effectiveness of problem based instruction: A comparative study of instructional methods and student characteriatics. The Interdisciplinary Journal of Problem-based Learning, 1(2), 49-69. 
Murthy, U., \& Kerr, D. (2003). Decision making performance of interacting groups: An experimental investigation of the effects of task type and communication mode. Information and Management, 40, 351-360.

Poindexter, S. (2003). Assessing active alternatives for teaching programming. Journal of Information Technology Education, 2.

Prichard, J., Stratford, R., \& Bizo, L. (2006). Team-skills training enhances collaborative learning. Learning and Instruction, 16, 256-265.

Quality Assurance Agency for Higher Education. (2007). Computing 2007. Retrieved from http://www.qaa.ac.uk/en/Publications/Documents/Subject-benchmark-statement-Computing.aspx.pdf

Salas, E., Cooke, N. J., \& Rosen, M. A. (2008). On teams, teamwork, and team performance: Discoveries and developments. Human Factors: The Journal of the Human Factors and Ergonomics Society, 540547.

Whatley, J. (2012). Evaluation of a team project based learning module for developing employability skills. Paper presented at the Informing Science and IT Education '12, Wollongong, Australia.

Yorke, M., \& Knight, P. (2003). The undergraduate curriculum and employability. Retrieved April 2003, 2003

\section{Biography}

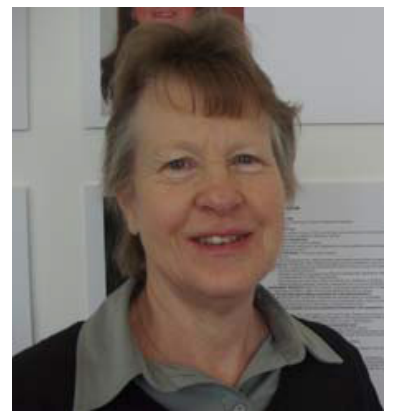

Janice Whatley is a now a part-time lecturer at the Manchester Metropolitan University in the UK. She supports computer laboratory sessions in IS, Multimedia and Databases, as well as Professional Development tutorials. Janice's main role is as co-ordinator of the Live Projects scheme, sourcing suitable projects from external organisations for student teams as part of their Professional Development. Janice has a doctorate in information systems from the University of Salford, within which the Guardian Agent system for supporting student team projects was created. Janice has also published in the areas of improving teaching and learning for students in higher education, and developing IT and team working skills. Janice is also interested in encouraging collaboration between students, having recently co-ordinated the European funded CAB Project, to enable students to learn through collaborating online with students from other European countries. 